\title{
Does Health Insurance give Us an Assurance? A Study on the Extent of Coverage of Health Insurance at a Tertiary Care Hospital in North India
}

\author{
${ }^{1}$ Kanika Jain, ${ }^{2}$ Sujeet K Sinha, ${ }^{3}$ Deepti Jain, ${ }^{4}$ Reena Kumar
}

\begin{abstract}
Introduction: Health insurance is emerging fast as an important mechanism to finance health care needs of the people. Complexity of the health insurance industry has been much talked about and less understood in the Indian scenario. Hence, it is imperative to assess the level of awareness that the population has with respect to health insurance policies.
\end{abstract}

Materials and methods: Cross-sectional prospective study conducted over a period of 6 months, at the third-party administrator (TPA) desk of the hospital. The data was collected using a preformed close-ended questionnaire after obtaining consent from all the participants. Only patients admitted in the hospital availing cashless hospitalization were included in the study. The study was undertaken with the objective to determine the level of awareness about insurance policies and procedures among those insured and identify the problems faced by those insured when availing cashless treatment. Responses to the variables in the questionnaire were compiled and tabulated using Excel 2010.

Results: Response rate of $76 \%$ was observed. $56 \%$ of the study population were planned admissions and $44 \%$ were admitted through emergency department. The study showed that about $56 \%$ of the principal policy holders were between 30 and 50 years of age. The awareness regarding the terms and conditions of the health care insurance policy and the servicing TPA was found to be $70 \%$. However, on interacting with patients it came to light that despite being appraised by their insurance agent, they faced challenges while availing health care benefits under health care insurance and were ignorant about the procedure involved.

For the current admission, in $78 \%$ of the cases, the TPA responded within 24 hours of intimation; however, in 22\% cases there were delays in response from the TPA mostly attributed to communication gap between the Insurance Company and the TPA. Preexisting disease was not covered in $14 \%$ cases. $82 \%$ cases had to wait for more than 2 hours for the final clearance from the TPA. Over the years, as ascertained in 2016 also, the scenario of insurance has not undergone significant change.

\footnotetext{
${ }^{1,2}$ Senior Resident, ${ }^{3}$ Resident, ${ }^{4}$ Additional Director

1,2Department of Hospital Administration, All India Institute of Medical Sciences, New Delhi, India

${ }^{3,4}$ Department of Hospital Administration, Sir Ganga Ram Hospital, New Delhi, India
}

Corresponding Author: Kanika Jain, Senior Resident Department of Hospital Administration, All India Institute of Medical Sciences, New Delhi, India, Phone: +919810949600 e-mail: kanika_24us@yahoo.com
Conclusion: Strategies to optimize claims by bringing about a uniformity in the rates being charged by the hospitals for different procedures are needed to increase coverage.

Keywords: Awareness, Health insurance, Third-party administrators.

How to cite this article: Jain K, Sinha SK, Jain D, Kumar R. Does Health Insurance give Us an Assurance? A Study on the Extent of Coverage of Health Insurance at a Tertiary Care Hospital in North India. Int J Res Foundation Hospc Health Adm 2016;4(1):25-30.

\section{Source of support: Nil}

Conflict of interest: None

\section{INTRODUCTION}

Health, like education, should be essential and should be freely available to all the citizens of a country. With rising health care costs, it has become imperative to make quality health care affordable for all the citizens irrespective of their income. Unlike many developed countries who spend 6 to $8 \%$ of their GDP on health, India barely spends $4 \%$ of its GDP on health. ${ }^{1}$ This low priority accorded to health has resulted in poor infrastructure and lack of advanced therapeutic and diagnostic facilities in public sector hospitals. Hence, the public has to look toward the private hospitals for such treatments. At present, as many as 135 million Indians do not have access to health services. ${ }^{2}$

The World Health Report of 2010, entitled Health Systems Financing: The Path to Universal Coverage, showed that over a billion people are unable to use the health services they need, while a 100 million people are pushed into poverty and 150 million people face financial hardship because they have to pay directly for the health services they use at the point of delivery. ${ }^{3}$ Advancement of medical technology and the increase in cost have necessitated the exploration of better health financing options to manage problems arising out of increasing health care costs. Health insurance is emerging fast as an important mechanism to finance health care needs of the people. However, the complexity of the health insurance industry has been much talked about and less understood, especially in the Indian scenario. Only a small section 
of the society have their health care covered. ${ }^{4}$ The lower socio-economic group sometimes falls out of the coverage because of nonaffordability.

Health insurance is a protection scheme to take care of health of a person and one can avail the benefit by buying a policy from an insurance company or an insurance agent. Health insurance schemes are particularly important for such people, especially from the lower income group so as to provide them with adequate cover in event of any mishap or illness. ${ }^{5}$ Health insurance not only promises payment to the insured in the event of sickness or injury, but also ensures that no compromises are made in the treatment for wants of funds. ${ }^{6}$ Currently, the trend of some of the reputable companies is to build in a health insurance policy as a benefit to their employees. At present, there is no universal health insurance in India and is limited to industrial workers and their families or to people who can afford to purchase such a scheme. ${ }^{7}$

The country has a number of public health insurance schemes, such as the Employees State Insurance Scheme, Central Government Health Scheme (CGHS), ECHS for the defense services personnel, and health care schemes for employees working in the railways or any public sector undertakings. ${ }^{4}$ Besides the public health insurance schemes, there are a number of private players in the country which provide health insurance to a number of people based on the premium paid by the insured to the company. The Insurance Regulatory Development Authority (IRDA) is the agency responsible for recognizing the various health insurance companies in India. There were 29 nonlife insurers in India in 2013 which covered health. ${ }^{8}$ Despite this, health care insurance market in India is yet to make a dent in the sector, with only 3.4 to 3.5 million members covered.

The third-party administrators (TPA - Health Services) were introduced into the insurance industry through a notification of IRDA (TPA - Health Services). The IRDA defines TPA as "an insurance intermediary licensed by the Authority who either directly or indirectly, solicits or effects coverage of, underwrite, collect, charge premium from an insured, or adjust or settle claims in connection with health insurance, except as an agent or broker or an insurer." ${ }^{\prime 10}$ The basic role of a TPA is to function as an intermediary between the insurer and the insured by providing administrative functions. The IRDA has granted license to 30 TPAs till June $2014 .{ }^{10}$ The introduction of these intermediaries in the sector has benefitted both the insured and the insurer. While the insurers are benefited by reduction in their administrative costs, the insured is benefited by better service. ${ }^{10}$

An insurance company may also use a TPA to manage its claims processing, provider networks, utilization review, or membership functions. While some TPAs may operate as units of insurance companies, they are often independent. Given the demand and supply complexities in health insurance and health care markets, the TPAs provide an important link between insurance companies, health care providers, and policy holders. The core product or service of a TPA is ensuring cashless hospitalization to the policy holders. ${ }^{3,11,12}$ The TPAs require skills to develop networks, manage finance, and for delivery of appropriate health care services to its clients. The TPAs have a wider role to play in ensuring standardization of charges and managing cashless services in health insurance. However, their actual roles and responsibilities have remained less understood, less clear, and much debated. ${ }^{11}$

The backbone of TPA is information management system. Analysis of data regarding hospital admissions across the network, analysis of treatment, tracking documents pertaining to each case, and tracking shortfalls in claims are essentials of claim management. ${ }^{12}$

The study was conducted at a 650 bedded, multispecialty, tertiary care, not for profit trust hospital in Delhi with the objective to determine the level of awareness about insurance policies among the inpatients availing cashless hospitalization. Further, the study aimed at identifying the problems faced by those insured while availing the said facility.

\section{MATERIALS AND METHODS}

This cross-sectional prospective study was conducted over a period of 6 months from July to December 2011 in a 650 bedded, tertiary care charitable trust hospital situated in Delhi. The existing process of cashless hospitalization in the hospital was studied and thereby close-ended questionnaire was designed, which was pilot tested before using the study. The data was collected after obtaining consent from all the participants. Confidentiality of the participants was ensured at every stage of the study and anonymized data was used for analysis.

The questionnaire had 31 items and was divided into three sections: Demographic profile, awareness about the health care insurance, and insurance process for current admission. The study sample was decided by taking the $10 \%$ of the total inpatients admission in a week availing health care insurance. Randomly selected 100 patients were studied. Questionnaires distributed were more than the study sample to achieve the requisite sample size. Sample included all patients who had an insurance cover and went through the procedure of applying to avail the cashless hospitalization. The study population included emergency cases for which insurance authorization request was sent after admission and planned inpatient 
admission which had necessary TPA-related processing done prior to admission.

Any patient suffering from any cardiovascular, nervous, mental, or physical pathology were excluded from the study. Responses to the variables in the questionnaire were compiled and tabulated.

A short study was again conducted using the same questionnaire in June, 2016 to assess the current situation. In this study, questionnaires were administered to 20 patients fulfilling the inclusion criteria mentioned above.

\section{OBSERVATIONS AND RESULTS}

The health care organization is a leading 650 bedded, multispecialty, tertiary care, not for profit trust hospital, successfully run by a highly competent and strong team of consultants specialized in their respective fields providing comprehensive medical care on its over 800 beds. The hospital is also a leading Academic Centre and is recognized as a Research Institute by the Department of Scientific and Industrial Research, Government of India. The hospital has produced numerous collaborative research programs, which have been recognized nationally and internationally. Annually, the hospital registers more than 4 lakh outpatients and 50,000 inpatients with more than $90 \%$ occupancy at all times. Over 24,000 surgeries take place in 24 seamless and world-class stainless steel modular operation theatres.

Response rate of $76 \%$ was observed. $56 \%$ of the study population were planned admissions and $44 \%$ were admitted through emergency department. The study showed that about $56 \%$ of the principal policy holders were between 30 and 50 years of age. Only 6\% of study population composed of retired individuals. $42 \%$ of the respondents had their parents, spouses, and children covered under the insurance. $86 \%$ of the policy holders were income tax payers, thus meaning that the insurance is majorly availed by the people employed in organized sectors (public and private). Approximately 52\% of the respondents were in service and $42 \%$ were self-employed. It shows that awareness about the insurance is fairly similar in both the groups. Of these $52 \%$ were salaried, $40 \%$ were insured under the corporate insurance policies, and $60 \%$ had purchased the health care insurance policies on their own (Table 1).

The awareness regarding the terms and conditions of the health care insurance policy and the servicing TPA was found to be $70 \%$. However, on interacting with patients it came to light that despite being appraised by their insurance agent, they faced challenges while availing health care benefits under health care insurance and were ignorant about the procedure involved. Few of them were even not aware about the diseases covered under the health care insurance. It was also found that the change in the servicing TPA was not being communicated to them and became aware once they applied for a claim under health care insurance.

Table 2 depicts the details of the health care insurance policy subscribed by the study participants. For the current admission, approximately $40 \%$ of the insurance cases were decided in the first instance itself, while for remaining additional information requests were received. In $78 \%$ of the cases the TPA responded within 24 hours of intimation, however in $22 \%$ cases there were delays in response from the TPA mostly attributed to communication gap between the Insurance Company and the TPA, either regarding the renewal or with regards to the change in TPA. In $44 \%$ of the cases no conditions were attached to the grant of approval for the claim made under health care insurance (Graph 1). In the rest of the cases some limitations to the extent of coverage were flagged. In $26 \%$ cases there was a capping on the room rent being

Table 1: Demographic profile of the patients

\begin{tabular}{|c|c|c|c|c|c|}
\hline Questions & & & & & Total \\
\hline \multirow[t]{2}{*}{ Age of the principal policy holder } & Below 30 years & $30-40$ years & $40-50$ years & Above 50 years & \\
\hline & 18 & 34 & 22 & 26 & 100 \\
\hline \multirow{2}{*}{ Level of education } & Matric & Undergraduate & Graduate & Postgraduate & \\
\hline & 4 & 8 & 44 & 44 & 100 \\
\hline \multirow[t]{2}{*}{ No. of dependent members } & None & Spouse & Spouse, children & Spouse, children, parents & \\
\hline & 2 & 22 & 34 & 42 & 100 \\
\hline \multirow[t]{2}{*}{ Age of the elder most member covered } & Below 40 years & $40-60$ years & $60-70$ years & above 70 years & \\
\hline & 22 & 46 & 26 & 6 & 100 \\
\hline \multirow[t]{2}{*}{ Whether self-employed or in service } & Self-employed & Salaried & Retired & & \\
\hline & 42 & 52 & 6 & & 100 \\
\hline \multirow[t]{2}{*}{ Total annual income (in Rs.) } & Up to 2 lacs & $2-5$ lacs & $5-10$ lacs & More than 10 lacs & \\
\hline & 14 & 36 & 30 & 20 & 100 \\
\hline \multirow[t]{2}{*}{ Whether income tax payer } & Yes & No & & & \\
\hline & 86 & 14 & & & 100 \\
\hline
\end{tabular}




\begin{tabular}{|c|c|c|c|c|c|}
\hline Questions & & & & & Total \\
\hline $\begin{array}{l}\text { If insurance cover provided by employer } \\
\text { or enrolled by self }\end{array}$ & $\begin{array}{l}\text { Corporate insurance } \\
40\end{array}$ & $\begin{array}{l}\text { Personal insurance } \\
60\end{array}$ & & & 100 \\
\hline $\begin{array}{l}\text { Educated about policy terms and conditions } \\
\text { by the company/insurance agent? }\end{array}$ & $\begin{array}{l}\text { Yes } \\
72\end{array}$ & $\begin{array}{l}\text { No } \\
28\end{array}$ & & & 100 \\
\hline $\begin{array}{l}\text { Awareness about servicing TPA at the time } \\
\text { of admission }\end{array}$ & $\begin{array}{l}\text { Yes } \\
70\end{array}$ & $\begin{array}{l}\text { No } \\
30\end{array}$ & & & 100 \\
\hline Insured for how long & $\begin{array}{l}\text { 1st year } \\
12\end{array}$ & $\begin{array}{l}\text { 2nd year } \\
18\end{array}$ & $\begin{array}{l}3-5 \text { years } \\
34\end{array}$ & $\begin{array}{l}<5 \text { years } \\
36\end{array}$ & 100 \\
\hline Sum (in Rs.) for which insured & $\begin{array}{l}\text { Less than } 50,000 /- \\
2\end{array}$ & $\begin{array}{l}\text { Up to } 1 \text { lac } \\
10\end{array}$ & $\begin{array}{l}\text { Up to } 3 \text { lacs } \\
68\end{array}$ & $\begin{array}{l}\text { More than } 3 \text { lacs } \\
20\end{array}$ & 100 \\
\hline
\end{tabular}

sanctioned. In another $14 \%$ of the cases a preexisting disease was not covered. In $54 \%$ of the cases an enhancement of the sum approved was required and this caused a delay in the patient being discharged from the hospital. $51 \%$ cases had to wait for more than 2 hours for the final clearance from the TPA, in 31\% cases this wait extended beyond 4 hours (Graph 2).

Of the 44 respondents who had availed insurance benefits earlier, only 26 were approved for cashless hospitalization while others were asked to get the reimbursement done. Of these, in 10 cases the total amount was reimbursed and in 8 cases partial deductions were made (Graph 3). The enquiry into the kind of deductions made was beyond the scope of the study. Of the total, 12 cases were settled within 45 days of filing for reimbursement while rest were settled within 3 months of filing for claim. The previous claim history of the study participants is given in Table 3.

In the short study, $55 \%$ admissions were planned admissions with about $60 \%$ of the principal policy holders between 30 and 50 years of age. Half the respondents were in service and the other half were self-employed.

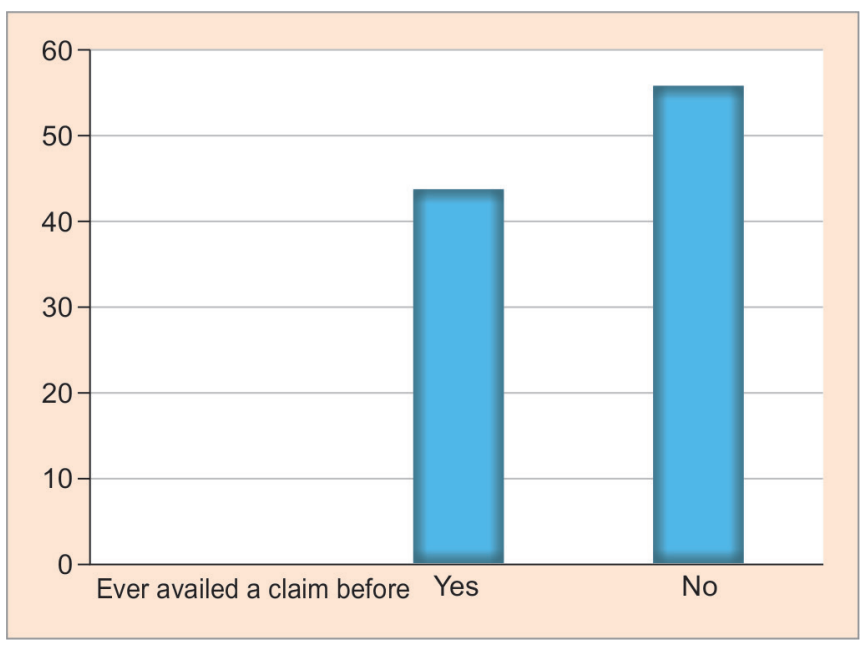

Graph 1: Previous claim status
Awareness across all respondents was similar to the results observed in the study conducted in 2011. However, in the current study it was found that the hours taken to process the claim has reduced from 6 hours in the earlier studies to less than 4 hours in over $80 \%$ cases (Table 4 , Graph 4). In addition, the respondents also stated that they had a wider choice of hospitals to go to and they were also getting cashless benefits for certain outpatient benefits. In addition, claims for reimbursements have reduced in consonance with the increase in the number of hospitals being empaneled by individual insurance companies.

\section{DISCUSSION}

In the current study, it was deduced that most of the principal policy holders belonged to the productive age group (30-50 years) which is line with the conclusions drawn in a number of studies conducted earlier on the subject. $^{13-15}$ Similarly, earlier studies have come to the conclusion that income was one of the most important determinant to purchase insurance, which also holds true in this study. ${ }^{16-18}$

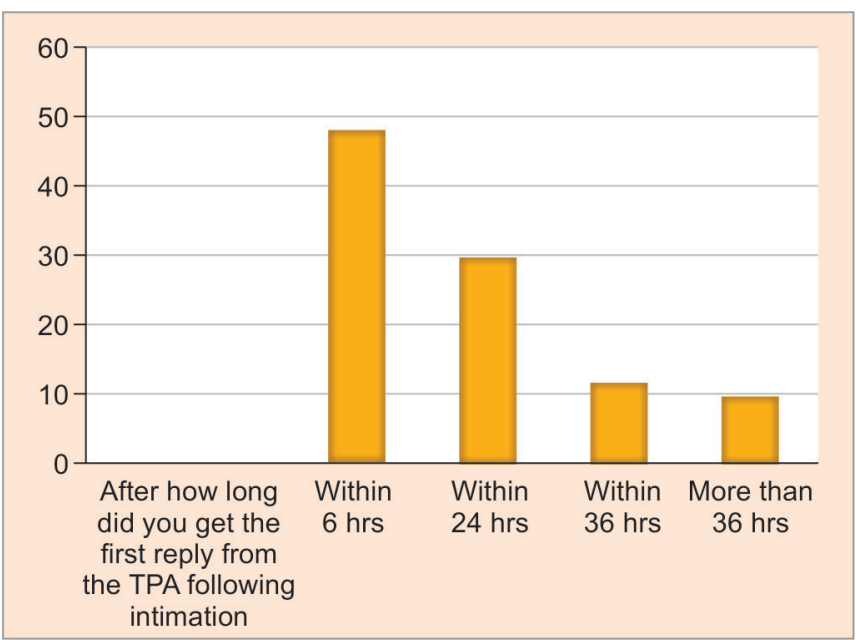

Graph 2: Time taken by the TPA to give initial response 


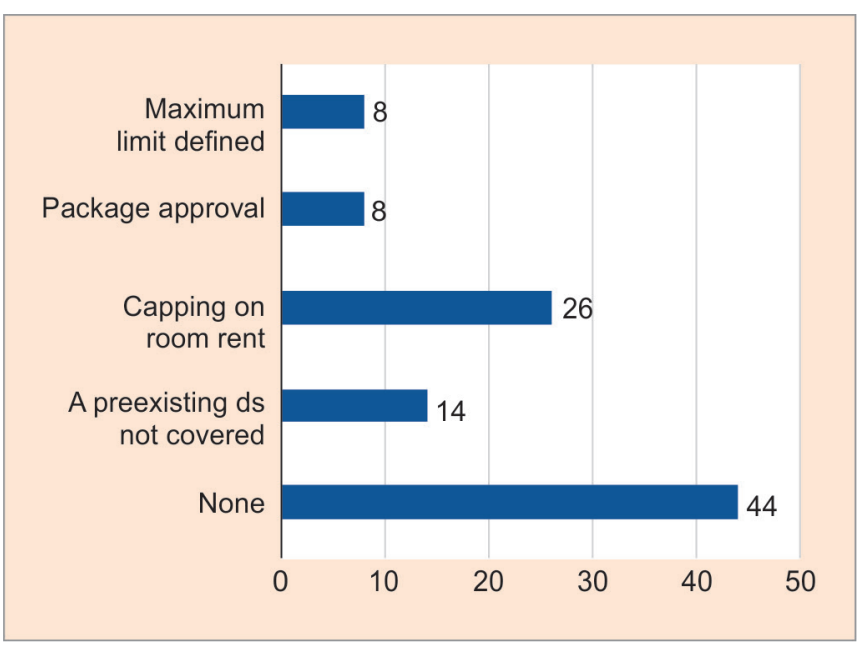

Graph 3: Conditional approvals

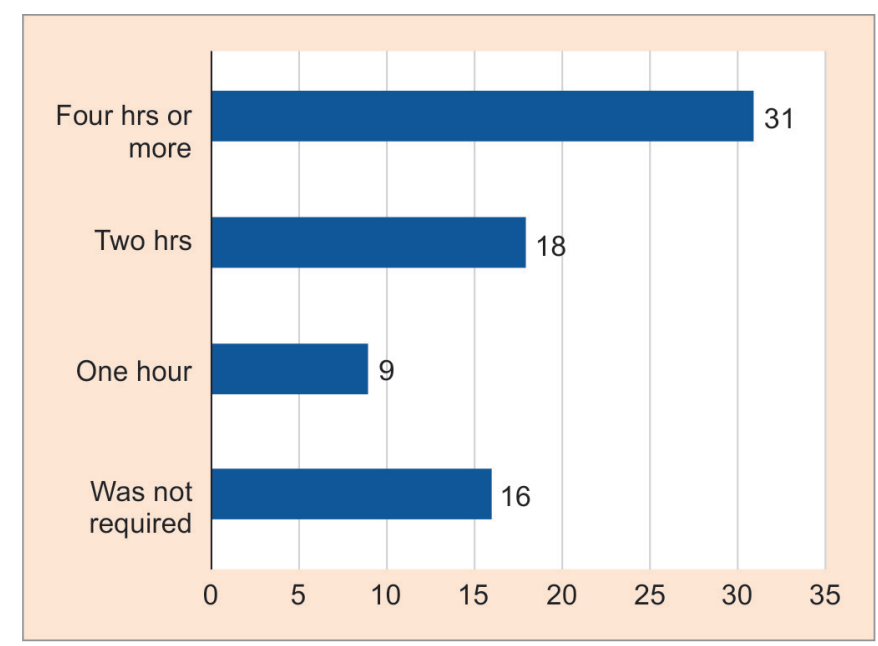

Graph 4: Time taken by TPA for final clearance at the time of discharge
In a study done by Bhatt et $\mathrm{l}^{10}$ in the Indian subcontinent revealed that the policy holders have very little knowledge and awareness about the empaneled hospitals for cashless hospitalization services and the existence of TPA, which is the reason why they rely heavily on insurance agents. Health care providers experience substantial delay in settling of their claims by the TPAs. The authors of this study observed similar experience despite greater penetration of insurance in an increasingly privatized health care environment over the decade.

Though the need for insurance is highest in the lower strata of the society, only $14 \%$ were nonincome tax payers, thus meaning that the insurance is majorly availed by the organized sector of the society. Though the aging population has increased with clear needs for greater

Table 3: Previous claim history

\begin{tabular}{|c|c|c|c|c|}
\hline \multicolumn{4}{|l|}{ Questions } & \multirow{2}{*}{$\frac{\text { Total }}{44}$} \\
\hline How many times have you availed of the insurance & Once & 2-5 times & More than 5 times & \\
\hline benefit in single financial year & 26 & 18 & & \\
\hline \multirow[t]{2}{*}{$\begin{array}{l}\text { If more than once was it for the same beneficiary and } \\
\text { illness }\end{array}$} & $\begin{array}{l}\text { Yes but not for the } \\
\text { same illness }\end{array}$ & $\begin{array}{l}\text { Yes but not for the } \\
\text { same beneficiary }\end{array}$ & $\begin{array}{l}\text { Yes for same beneficiary } \\
\text { and same illness }\end{array}$ & 18 \\
\hline & 3 & 4 & 11 & \\
\hline \multirow{2}{*}{$\begin{array}{l}\text { Has there been any refusal for coverage for repeat } \\
\text { hospitalizations }\end{array}$} & Yes & No & & 44 \\
\hline & 4 & 40 & & \\
\hline \multirow{2}{*}{$\begin{array}{l}\text { Have you increased the sum for which you were insured } \\
\text { at the time of registering the policy? }\end{array}$} & Yes & No & & 44 \\
\hline & 10 & 34 & & \\
\hline \multirow{2}{*}{$\begin{array}{l}\text { Is there any preexisting disease that the company has } \\
\text { identified as not covered }\end{array}$} & Yes & No & & 44 \\
\hline & 6 & 38 & & \\
\hline
\end{tabular}

Table 4: Current admission

\begin{tabular}{|c|c|c|c|c|c|c|}
\hline Questions & & & & & & Total \\
\hline \multirow[t]{2}{*}{$\begin{array}{l}\text { After how long did you get the first } \\
\text { reply from the TPA following intimation }\end{array}$} & Within 6 hours & Within 24 hours & Within 36 hours & $\begin{array}{l}\text { More than } \\
36 \text { hours }\end{array}$ & & 100 \\
\hline & 48 & 30 & 12 & 10 & & \\
\hline \multirow{2}{*}{$\begin{array}{l}\text { How many queries were raised by the } \\
\text { TPA before the final decision }\end{array}$} & None & One & two & More than two & & 100 \\
\hline & 40 & 30 & 18 & 12 & & \\
\hline \multirow[t]{2}{*}{$\begin{array}{l}\text { Were there any conditions applied on } \\
\text { the approval that was granted to you }\end{array}$} & None & $\begin{array}{l}\text { A preexisting } \\
\text { ds. not covered }\end{array}$ & $\begin{array}{l}\text { Capping on } \\
\text { room rent }\end{array}$ & $\begin{array}{l}\text { Package } \\
\text { approval }\end{array}$ & $\begin{array}{l}\text { Maximum } \\
\text { limit defined }\end{array}$ & 100 \\
\hline & 44 & 14 & 26 & 8 & 8 & \\
\hline \multirow{2}{*}{$\begin{array}{l}\text { Was there a need for enhancement of } \\
\text { the limit approved }\end{array}$} & Yes & No & & & & 80 \\
\hline & 54 & 26 & & & & \\
\hline
\end{tabular}


coverage, a mere $6 \%$ coverage may also reflect the higher premiums that older clientele would need to pay.

Based on the observations above, the following recommendations can be deduced from the study. The communication between the Parent Insurance Company and the TPA needs to be improved in order to make the claim processing smooth and hurdle-free. This can be achieved through the cross-linking of the databases of the various TPAs of an insurance company in order to solve the renewal-related issues which are responsible for a considerable portion of delays and confusions.

The package rates for all common cases requiring hospitalization should be determined by discussions with the provider hospitals considering their requirements and constraints. We can also think in terms of promoting day care procedures as these cut the costs to a large extent.

Working in the direction of preventive and promotive aspects of health will decrease the health care costs in the long term due to timely diagnosis and timely intervention. This can be achieved by providing a free periodic health checkup to the beneficiaries.

The study was conducted within a limited timeframe and few assumptions were made during the course of the study. Since the data was collected from the TPA desk, it is possible that those who have been denied a cashless hospitalization might have been missed out.

\section{CONCLUSION}

Although the awareness and utilization of the insurance benefit is fairly satisfactory in the people working in the organized sector, but a lot needs to be done to bring the people working in the unorganized sector under the umbrella of the health care insurance. The process of availing cashless hospitalization has to be made less cumbersome as the beneficiary has to run from pillar to post to avail the benefit when a family member is already sick and needs attention. In order to increase coverage, innovative solutions are needed in terms of optimizing the claims by bringing about a similarity of the rates charged by the hospitals.

\section{ACKNOWLEDGMENT}

We would like to acknowledge Dr Vijaydeep Siddharth, Assistant Professor, Department of Hospital Administration, All India Institute of Medical Sciences, Delhi for his intellectual and critical input

\section{REFERENCES}

1. OECD. Focus on health spending. OECD Health Statistics; 2015 Jul. p. 1-8.
2. Purohit BC. Private initiatives and policy options: recent health system experience in India. Health Policy Plann March 2001 16(1):87-97. Available from: http://heapol.oxfordjournals. org/content/16/1/87.full.pdf.

3. Xu K, Evans DB, Carrin G, Aguilar-Rivera AM, Musgrove P, Evans T. Protecting households from catastrophic health spending. Health Aff (Millwood) 2007 Jul-Aug;26(4):972-983.

4. Cameron AC, Trivedi PK, Milne F, Piggott J. A microeconomic model of the demand for health care and health insurance in Australia. Rev Econ Stud 1988 Feb;55(181):85-106.

5. Savage E, Wright D. Health insurance and health care utilization: theory and evidence from Australia 1989-90. Mimeograph B2 - Mimeograph. Sydney, University of Sydney; 1999.

6. Ngui M, Burrows C, Brown K. Health insurance choice: an econometric analysis of A.B.S. health and health insurance surveys, economics and health. Proceedings of the Australian Conference of Health Economists B2; 1989. p. 172-194.

7. Hurd MD, McGarry K. Medical insurance and the use of health care services by the elderly. J Health Econ 1997 Apr;16(2):129-154.

8. Jutting J. Strengthening social security systems in rural areas of developing countries. ZEF discussion paper on development policy, university of bonn - center for development research June 1999.

9. O'Connell TS (2012) National health insurance in Asia and Africa: advancing equitable social health protection to achieve universal health coverage. http://www.unicef.org/ socialpolicy/files/National_health_insurance_in_Asia_and_ Africa-Final-22 May 2012.pdf Accessed: 12 March 2016

10. Bhat R, Maheshwari S, Saha S. Third party administrators and health insurance in India: perception of providers and policyholders; Indian Institute of Management Ahmadabad, 2005. p. 1-24.

11. Scotton RB. Membership of voluntary health insurance. Econ Record 1969 Mar;45(1):69-83.

12. Propper C. An econometric analysis of the demand for private health insurance in England and Wales. Appl Econ 1989;21(6):777-792.

13. Harrington $S$, Miller T. Competitive markets for individual health insurance. Health Aff (Millwood) 2002 Jul-Dec;(Suppl) Web Exclusives:W359-W362.

14. Non life Insurers (accessed 2016 Mar 11). Available from: https://www.irdai.gov.in/ADMINCMS/cms/NormalData_ Layout.aspx?page $=$ PageNo264\&mid=3.2.10.

15. Pranav S. Health insurance companies in India - a comparative study. 2013 Apr;13(4):136-144.

16. Health Insurance and Third Party Administrator - HDFC ERGO [Internet]. Hdfcergo.com. 2016 [cited 2016 May 9]. Available from: https://www.hdfcergo.com/article-healthinsurance/health-insurance-and-third-party.html.

17. Viswanathan S, Narayanan GS. Poor hospital network of Third Party Administrators dents mediclaim cashless service plan. Express Health care Management; Apr 2003.

18. Gupta I, Roy A, Trivedi M. Third Party Administrators theory and practice. Econ Polit Wkly 2004 Jul;XXXIX(28).

19. Third Party Administrator (TPA). Role of TPA in Health Insurance India, Medimanage [Internet]. Medimanage.com. 2016 [cited 2016 May 9]. Available from: http://www.medimanage.com/my-health-insurance/articles/tpa-crackingthe-mystery-around-tpa.aspx. 